\title{
Reseña
}

\section{¡QUÉ PASA CON SU POSGRADO, MAESTRO!}

\begin{abstract}
Memoria razonada sobre la aplicación de Subproyecto Apoyo a la formación avanzada de los docentes del D.C., ejecutado por el Instituto para la Investigación Educativa y el Desarrollo Pedagógico de Santafé de Bogotá, entre los meses de Septiembre y Diciembre de 1997
\end{abstract}

Tesis de grado de la Maestría en Educación, con énfasis en Evaluación Escolar y Desarrollo Educativo Regional (Universidad Pedagógica Nacional).

Autor: Edgar Torres Cárdenas

Director: Guillermo Bustamante Zamudio Jurados: Fabio Jurado Valencia y Fabio Lozano Santos

Este trabajo tiene como objeto entrecruzar tres voces: por una parte, los lineamientos de política del Instituto para la investigación Educativa de Santafé de Bogotá -IDEP-, de otra parte, la orientación de los proyectos de trabajo de grado que los docentes del Distrito Capital dicen poner en ejecución como parte de su trabajo académico de estudiantes de diversos niveles de formación avanzada y, de otra parte, las voces que, en los discursos de quienes los cursan, identifican a las diversas ofertas de estudios de posgrado de distintas universidades. Para el efecto, se trabajó con la muestra constituida por los docentes oficiales (792, en total) que respondieron a una convocatoria del IDEP, realizada dentro de las políticas dé formar ciudad, para conseguir los objetivos académicos y educativos del gobierno Mockus, apoyando económicamente los estudios de posgrado de un grupo de docentes del Distrito

El trabajo consta de cuatro partes:

La primera dedicada a poner de manifiesto las condiciones del concurso $y$, por consecuencia, a explicitar los límites de la reflexión que el mismo permite. Esta parte se detiene sobre cuatro temas: el primero es la presentación del objeto del trabajo y la elec- ción de los límites del mismo, específicamente la manifestación de las perspectivas epistemológicas que permiten elegir la presentación del informe de investigación en forma de relato de la memoria. El segundo es la presentación de la correlación entre las políticas gubernamentales y las del IDEP, así como las implicaciones que de allí se derivan para el papel que juega la universidad en el mejoramiento de la calidad de la educación. El tercero es el examen de los textos de la convocatoria que, de manera particular, explicita el juicio desde y hacia donde se convocaba la participación de los docentes al concurso. El cuarto revela las expectativas del IDEP a través del análisis de los componentes de la ficha técnica que los docentes participantes llenaron como parte de su documentación.

La segunda parte está dedicada a poner de manifiesto los principios y formas de la evaluación. Allí se deșarrollan dos temas; el primero trata de los criterios, las estrategias, los instrumentos y la composición del equipo que realizó la evaluación de las solicitudes de los participantes. Este capítulo es crucial por cuanto expone la elección de la idea de transparencia evaluativa en cambio de la esperada objetividad, y justifica el riesgo de atenerse a ella para ejecutar un proceso de valoración de las solicitudes, cuyos resultados implicaban las aspiraciones de un gremio conflictivo y luchador por sus derechos y la realización de sus expectativas. El segundo tema hace referencia a las expectativas económicas de los participantes y los recursos presupuestales del IDEP, de donde se concluye el carácter realista de las solicitudes de los docentes frente a la escasez de los recursos.

La tercera parte presenta, de manera pormenorizada, los resultados del concurso. Mediante un apoyo de estadística elemental, el estudio cruza la concurrencia de las tres voces que son objeto del estudio, por cinco variables. La primera son los resultados globales obtenidos en cada uno de los campos a los que se aplica la evaluación y a los promedios de cada uno de ellos y del conjunto. La segunda, los resultados obtenidos de acuerdo con la participación del tipo de instituciones universitarias (privadas, públicas y extranjeras) en las cuales cursan sus estudios los docentes de la muestra. La tercera, los niveles de posgrado cursados por los docentes (especializaciones, maestrias y doctorados). La cuarta, los semestres que cursan los participantes en la convocatoria. La quinta, el área temática de los posgrados cursados por los docentes. En su conjunto, la investigación permite plantear, no tanto los resultados cuantitativos, como la construcción de las conjeturas que llevan, razonadamente, a los problemas de coherencia y entrecruzamiento que son el objeto del estudio.

La cuarta parte presenta las conclusiones del estudio en términos de desencuentro. En efecto: la investigación permite concluir que, a pesar del origen educativo de los integrantes del equipo de gobierno de la administración Mockus y del fundamento académico de sus políticas, no hay un concierto que permita la interacción planeada y concurrente de las políticas educativas de la administración, las voces y los discursos que los posgrados ponen en circulación y los proyectos y propuestas de trabajo de los docentes que cursan los estudios de formación avanzada. La ciudad en donde todos ponen para que todos ganen parece jugar con otros códigos de autorregulación distintos de los que presupone la acción comunicativa o, en su defecto, el modelo ciudadano europeo; códigos locales sin cuyo ejercicio sería imposible sobrevivir, a pesar de los esfuerzos de la razón pedagógica. 